\title{
Human blood monocytes support persistence, but not replication of the intracellular pathogen C. pneumoniae
}

\author{
Tanja Buchacher ${ }^{1}$, Herbert Wiesinger-Mayr ${ }^{2}$, Klemens Vierlinger ${ }^{2}$, Beate M Rüger ${ }^{3}$, Gerold Stanek ${ }^{4}$, \\ Michael B Fischer ${ }^{3,5+}$ and Viktoria Weber ${ }^{1,5^{*+}}$
}

\begin{abstract}
Background: Intracellular pathogens have devised various mechanisms to subvert the host immune response in order to survive and replicate in host cells. Here, we studied the infection of human blood monocytes with the intracellular pathogen C. pneumoniae and the effect on cytokine and chemokine profiles in comparison to stimulation with LPS.

Results: Monocytes purified from peripheral blood mononuclear cells by negative depletion were infected with C. pneumoniae. While immunofluorescence confirmed the presence of chlamydial lipopolysaccharide (LPS) in the cytoplasm of infected monocytes, real-time PCR did not provide evidence for replication of the intracellular pathogen. Complementary to PCR, C. pneumoniae infection was confirmed by an oligonucleotide DNA microarray for the detection of intracellular pathogens. Raman microspectroscopy revealed different molecular fingerprints for infected and non-infected monocytes, which were mainly due to changes in lipid and fatty acid content. Stimulation of monocytes with C. pneumoniae or with LPS induced similar profiles of tumor necrosis factor-alpha (TNF-a) and interleukin (IL)-6, but higher levels of IL-1 $\beta, I L-12 p 40$ and IL-12p70 for C. pneumoniae which were statistically significant. C. pneumoniae also induced release of the chemokines MCP-1, MIP-1a and MIP-1 $\beta$, and CXCL-8, which correlated with TNF-a secretion.

Conclusion: Infection of human blood monocytes with intracellular pathogens triggers altered cytokine and chemokine pattern as compared to stimulation with extracellular ligands such as LPS. Complementing conventional methods, an oligonucleotide DNA microarray for the detection of intracellular pathogens as well as Raman microspectroscopy provide useful tools to trace monocyte infection.
\end{abstract}

Keywords: Intracellular pathogens, Endotoxin, Monocytes, Cytokines, DNA microarray

\section{Background}

Microbial pathogens have developed various strategies to escape and alter host immunity to favor their survival within the host $[1,2]$. Intracellular pathogens, in particular, use host cells as a replicating niche, and their release from infected cells with subsequent infection of new

\footnotetext{
* Correspondence: viktoria.weber@donau-uni.ac.at

${ }^{\dagger}$ Equal contributors

'Christian Doppler Laboratory for Innovative Therapy Approaches in Sepsis, Danube University Krems, Krems, Austria

${ }^{5}$ Department for Health Sciences and Biomedicine, Danube University Krems, Krems, Austria

Full list of author information is available at the end of the article
}

cells may contribute to dissemination and persistence of infection.

Chlamydia pneumoniae is a Gram-negative, obligate intracellular bacterium causing respiratory infections, such as acute pneumonia, bronchitis, and sinusitis [3]. Furthermore, there is a growing body of evidence for association of persistent C. pneumoniae infections with a range of chronic diseases, such as atherosclerosis, asthma, arthritis, multiple sclerosis, Alzheimer's disease, and osteoporosis [4-10]. Chlamydiae exhibit a dimorphic life cycle with extracellular, infectious elementary bodies (EBs), and intracellular, noninfectious reticulate bodies (RBs) $[11,12]$. Transition into a state of persistence can be induced in vitro by factors such

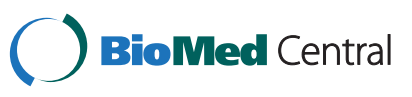

(c) 2014 Buchacher et al.; licensee BioMed Central Ltd. This is an Open Access article distributed under the terms of the Creative Commons Attribution License (http://creativecommons.org/licenses/by/4.0), which permits unrestricted use, distribution, and reproduction in any medium, provided the original work is properly credited. The Creative Commons Public Domain Dedication waiver (http://creativecommons.org/publicdomain/zero/1.0/) applies to the data made available in this article, unless otherwise stated. 
as penicillin, starvation, or maturation of the host cell. Among the susceptible host cells are the mucosal and vascular endothelium, smooth muscle cells, circulating monocytes, and tissue-specific macrophages [13]. C. pneumoniae can induce monocyte inflammatory cascades and modulate cellular lipid metabolism [14]. Human monocyte cell lines have been shown to transfer the pathogen to endothelial cells in vitro [15-17], and several lines of evidence propose a role of circulating monocytes as vehicle of its vascular dissemination [18]. Monocytes may traffic C. pneumoniae across the blood-brain-barrier, shed them in the central nervous system, and induce neuroinflammation $[19,20]$.

The detection of pathogens within immune cells is challenging, and their intracellular growth may prevent correct diagnosis and appropriate treatment. The value of blood cultures as a general diagnostic tool for pathogen detection is limited due to delayed availability of results and poor sensitivity for fastidious pathogens [21].

Here, we established an in vitro model for the infection of immune cells with intracellular pathogens and investigated cytokine and chemokine release from human blood derived monocytes infected with C. pneumoniae. To trace monocyte infection, we applied a combination of methods, namely immunofluorescence and real-time PCR (RT-PCR) as well as an oligonucleotide DNA microarray for intracellular pathogens. Finally, we used Raman microspectroscopy to identify infected monocytes based on altered biomolecule fingerprints.

\section{Results}

\section{Detection of $C$. pneumoniae by immunofluorescence}

C. pneumoniae was grown in HEp-2 cells, which are established for Chlamydia propagation [22]. Cells were lysed at $72 \mathrm{~h}$ post infection, and fractions of chlamydial elementary bodies were isolated and used to infect adherent monocytes. Infection was performed using $2 \times 10^{3}$ and $2 \times 10^{4}$ inclusion forming units (IFU) per $2 \times 10^{5}$ monocytes, further designated as high and low dose protocols, respectively. Mature chlamydial inclusions co-localized with LPS in infected HEp-2 cells, and chlamydial DNA could be visualized at $48 \mathrm{~h}$ post infection (Figure 1A, upper panel). In contrast to the clearly bordered chlamydial inclusions observed in HEp-2 cells, chlamydial LPS appeared in clusters of vesicles in the cytoplasm of monocytes (Figure 1A, middle panel). Reinfection of fresh HEp-2 cells with lysates derived from infected monocytes revealed no chlamydial inclusions (Figure 1A, lower panel), indicating the absence of viable pathogen. Monocyte infection rates as determined by immunofluorescence were 3-9\% for the low dose vs. $41-50 \%$ for the high dose infection (Figure 1B).

Detection of $C$. pneumoniae by DNA-microarray and RT- PCR Two DNA-based methods, RT-PCR and a novel DNA microarray, were employed to monitor C. pneumoniae infection of monocytes. RT-PCR revealed no significant changes in copy numbers of the intracellular pathogen over time (Figure 1C). No chlamydial DNA was detected in uninfected monocytes. In contrast, HEp-2 cells infected with $C$. pneumoniae exhibited an increase in the copy number of the $16 \mathrm{~S}$ rDNA gene transcripts after $48 \mathrm{~h}$ of infection (Figure 1D).

An oligonucleotide microarray was developed for the simultaneous detection of Bartonella, Bordetella, Chlamydia and Mycoplasma as described in Materials and Methods. The sequence of the chosen primer pair and oligonucleotide probes are summarized in Figure 2A. Red spots on the heatmap (Figure 2B) indicate strong hybridization of the selected oligonucleotide probes with their complementary PCR products, demonstrating the specificity of the microarray. Certain probes, such as Chlamydia spp. p4 showed weak cross-hybridization to Mycoplasma and Bordetella. To classify a hybridization pattern, the nearest shrunken centroid classification was used and validated in a leaveout cross-validation approach [23]. Relying on this analysis, the assay specificity for all 43 hybridizations was determined to be $100 \%$ at genus level and more than $84.1 \%$ at species level. Using this oligonucleotide microarray, DNA extracted from monocytes yielded a positive signal at 6 and $48 \mathrm{~h}$ post infection for the high and low dose protocol, respectively (Figure 2C).

\section{Detection of modified biomolecule patterns by Raman spectroscopy}

We recorded Raman spectra for monocytes infected with C. pneumoniae and for uninfected monocytes. The scores plot resulting after Principal Component Analysis (PCA) showed two clusters for uninfected and infected monocytes after $48 \mathrm{~h}$, which can be separated on PC1 (48\%), while no separation was seen after $6 \mathrm{~h}$ of infection (Figure 3A). Data of infected and uninfected cells after $48 \mathrm{~h}$ were compared in a mean spectra plot (Figure $3 \mathrm{~B}$ ) and certain wave number areas specific for infection were re-analyzed by PCA for clear separation (percentage value on $\mathrm{PC} 1>48 \%)$. According to this analysis, differences between infected monocytes and uninfected control were found in wavenumber regions $1645-1660 \mathrm{~cm}^{-1}$, 1430$1451 \mathrm{~cm}^{-1}, 1327-1356 \mathrm{~cm}^{-1}, 1290-1306 \mathrm{~cm}^{-1}$, and 888$934 \mathrm{~cm}^{-1}$, indicating changes in lipids, fatty acids, and nucleic acids in infected monocytes [24].

\section{Cytokine release from infected monocytes}

Cytokine release was assessed after monocyte infection with C. pneumoniae (Figure 4). Levels of tumor necrosis factor-alpha (TNF- $\alpha$ ) increased over $6 \mathrm{~h}$ after post infection with low dose C. pneumoniae or LPS and remained stable or slightly decreased at later time points. High dose C. pneumoniae induced an analogous kinetic pattern of TNF- $\alpha$ release with approximately five-fold higher TNF- $\alpha$ 

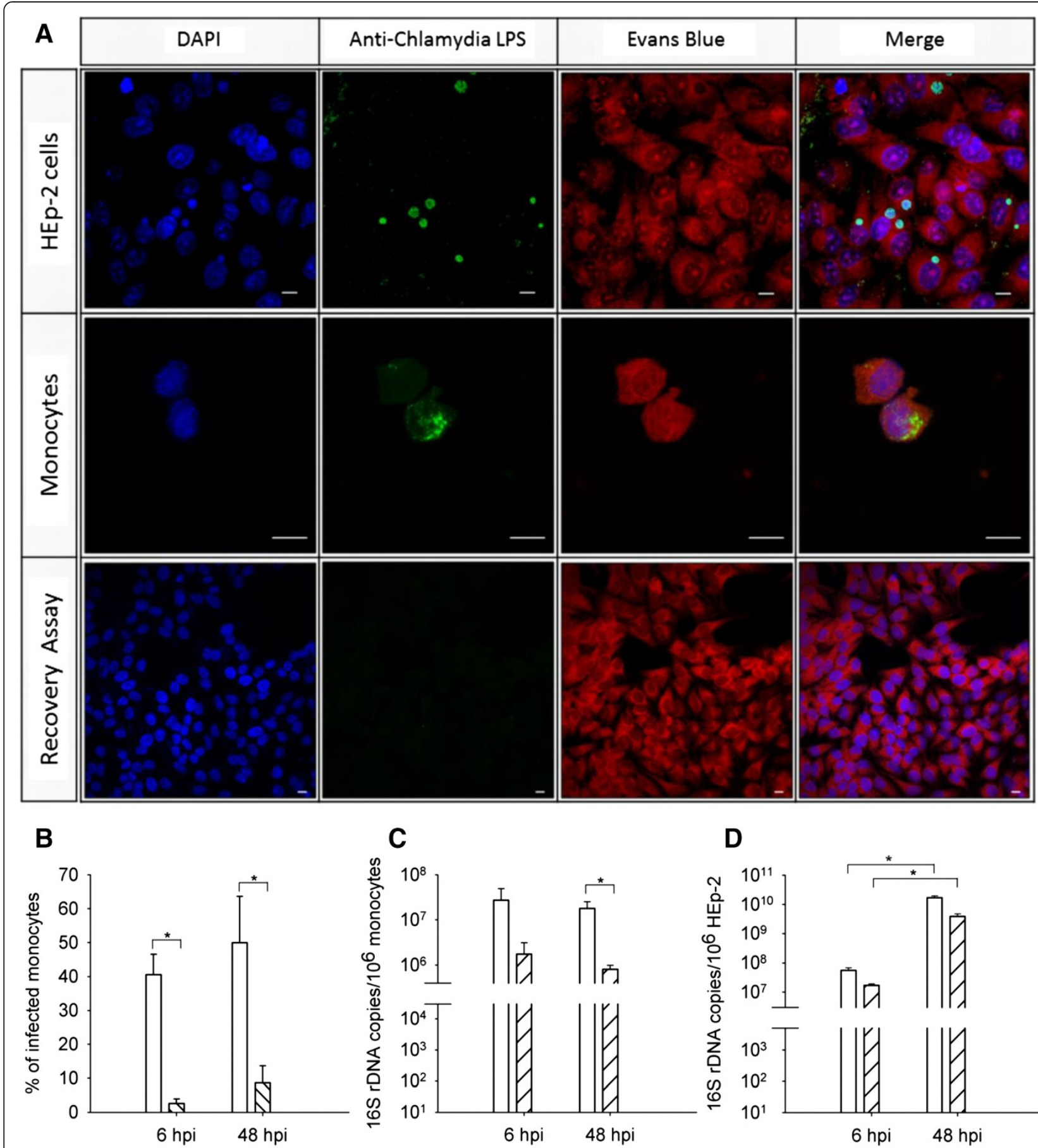

C

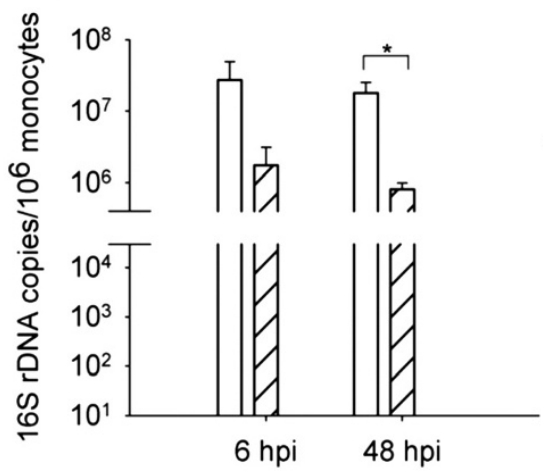

D

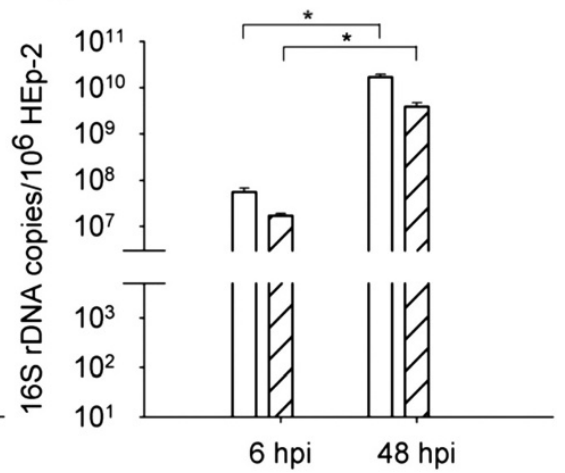

Figure 1 Detection of $C$. pneumoniae in HEp-2 cells and monocytes using immunofluorescence microscopy and RT-PCR. A) C. pneumoniae (green) was detected in HEp-2 cells (upper panel) and in adherent monocytes (middle panel) at 48 h post infection. Recovery of C. pneumoniae was evaluated by recultivating disrupted monocytes at $48 \mathrm{~h}$ post infection in HEp-2 cells (lower panel). Cells were counterstained with Evans Blue (red), and DNA was visualized with DAPI (blue). Chlamydial inclusions are clearly demarcated in HEp-2 cells, but appear diffuse in monocytes (scale bar $=10 \mu \mathrm{m}$ ). B) Monocyte infection was performed using $2 \times 10^{4}$ IFU (open bars) and $2 \times 10^{3}$ IFU (hatched bars) per $2 \times 10^{5}$ monocytes, respectively, and monocyte infection rates were determined by immunofluorescence. C) C. pneumoniae $16 \mathrm{~S}$ rDNA copies in monocytes and D) HEp-2 cells infected with $2 \times 10^{4}$ IFU (open bars), $2 \times 10^{3}$ IFU (hatched bars) and uninfected cells (grey bars) were quantified at 6 and 48 h post infection by RT-PCR. Concentrations are expressed as mean \pm SD for 3 independent experiments. * $\mathrm{P} \leq 0.05$ 


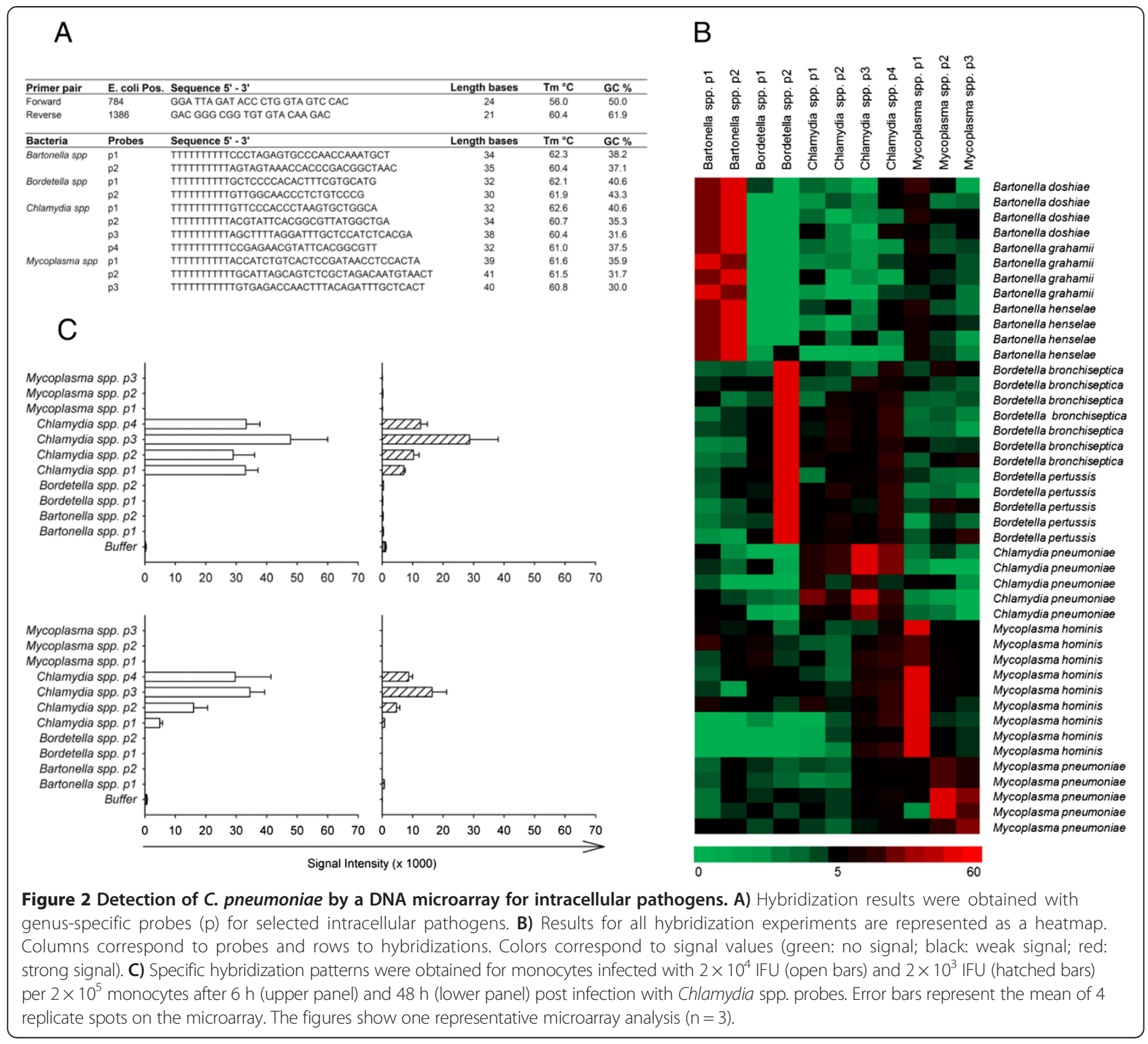

concentrations. Secretion of IL- 6 started at $6 \mathrm{~h}$ post infection for all stimuli with a continuous increase over $48 \mathrm{~h}$. High dose C. pneumoniae yielded about five-fold higher IL- 6 concentrations as compared to the lower dose.

While similar levels of TNF- $\alpha$ and IL- 6 were released after infection with low dose C. pneumoniae or stimulation with $1 \mathrm{ng} / \mathrm{mL}$ LPS, low dose $C$. pneumoniae induced higher levels of IL-1 $\beta$, IL-12p40 and IL-12p70 over time than LPS, which was shown to be statistically significant (Figure 4). Noteworthy, levels of IL-12p40 in the supernatant were about ten-fold higher than levels of IL-12p70, demonstrating that production of each of the subunits of IL-12 is independently regulated. The anti-inflammatory mediator IL-10 started to increase at $6 \mathrm{~h}$ post infection for all stimuli, but showed different kinetics for low dose C. pneumoniae and LPS. LPS yielded significantly higher levels of IL-10 than low dose C. pneumoniae at $6 \mathrm{~h}$ after stimulation, but this ratio was reversed over time, resulting in significantly higher IL-10 levels for low dose C. pneumoniae as compared to LPS after $48 \mathrm{~h}$. Cytokine levels released from mock-infected monocytes remained below the detection limit and did not differ from uninfected controls (medium alone).

\section{Chemokine release from infected monocytes}

Secretion of monocyte chemotactic protein (MCP)-1 and MCP-3 started at $24 \mathrm{~h}$ after monocyte infection with $C$. pneumoniae and continued to increase for up to $48 \mathrm{~h}$. LPS induced significantly lower amounts of both chemokines over time (Figure 5). Macrophage inflammatory protein (MIP)- $1 \alpha$ and MIP-1 $\beta$ release started at $6 \mathrm{~h}$ after monocyte infection with $C$. pneumoniae and continued to 


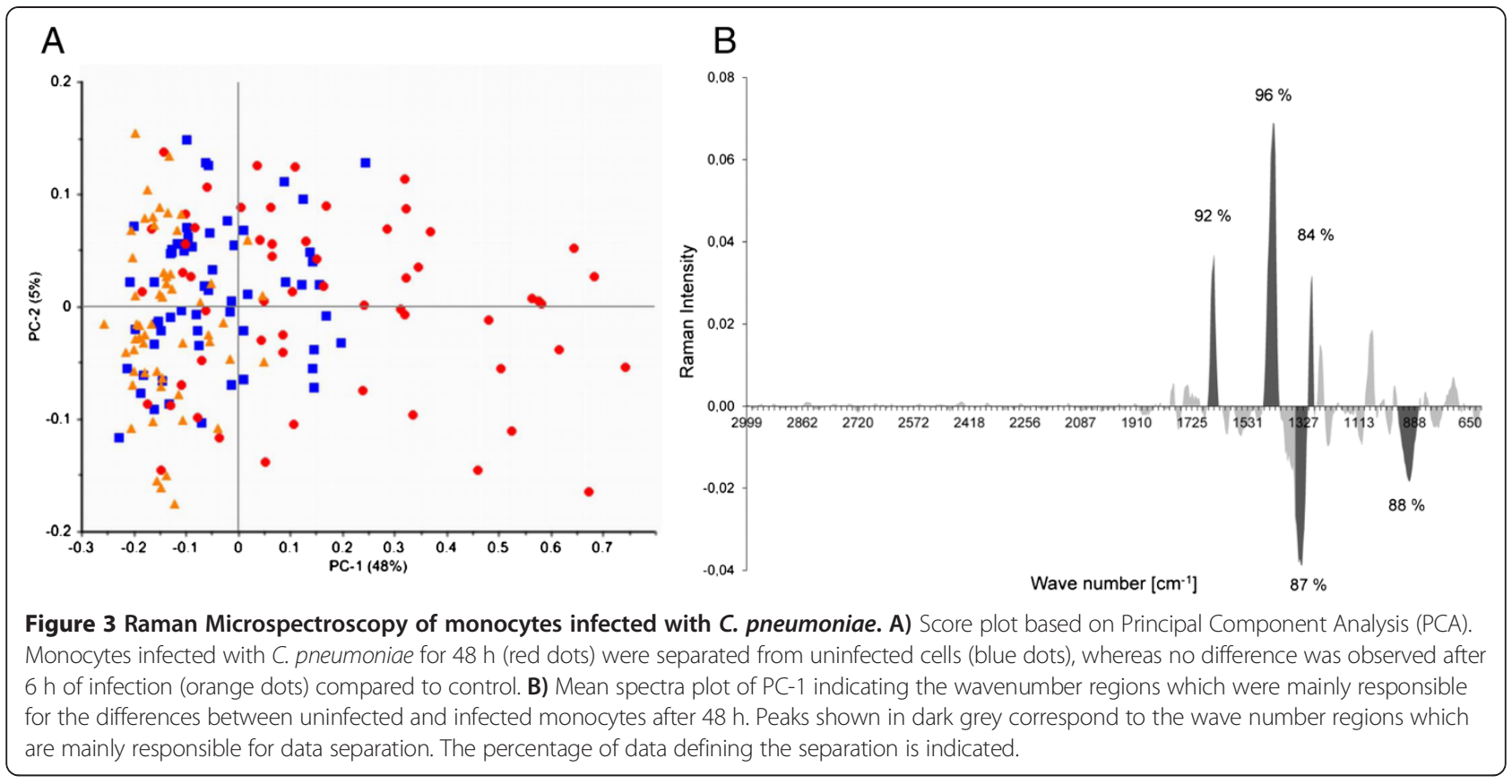

increase for up to $48 \mathrm{~h}$, while MIP-1 peaked at $24 \mathrm{~h}$ after stimulation with LPS and started to decrease thereafter. An analogous pattern was seen for IL-8 (CXCL-8), which increased continuously over $48 \mathrm{~h}$ after monocyte infection with C. pneumoniae, while levels peaked at $24 \mathrm{~h}$ upon LPS stimulation. Again, chemokine levels released from mock-infected monocytes remained below the detection limit.

\section{Discussion}

Monocytes and monocyte-derived macrophages are supposed to act as vectors for the systemic dissemination of C. pneumoniae [25]. Here, we established an in vitro model to study the activation of human blood monocytes with C. pneumoniae and to examine immune mediator profiles secreted by infected monocytes. To detect intracellular pathogen and to analyze the potential ability of monocytes to support Chlamydia replication, we applied a combination of RT-PCR and immunofluorescence as well as an oligonucleotide DNA microarray for intracellular pathogens. Immunofluorescence revealed numerous small vesicles containing clusters of chlamydial LPS in the cytoplasm of infected monocytes, but it failed to detect chlamydial DNA or typical chlamydial inclusions. HEp-2 cells, which were used to propagate C. pneumoniae, in contrast, allowed for the formation and growth of inclusions containing chlamydial DNA and LPS. RT-PCR did not reveal significant changes in copy numbers of the intracellular pathogen over time, which indicates persistence but not replication of internalized C. pneumoniae in monocytes under these experimental conditions. In line with this finding, no viable C. pneumoniae could be recovered in HEp-2 cells upon re-infection with lysates from monocytes infected with C. pneumoniae for $48 \mathrm{~h}$. This observation is in accordance with previously published data showing that $C$. pneumoniae does not replicate in freshly isolated monocytes, while monocytederived macrophages cultured for several days support the growth of chlamydial progeny [26,27]. Consistently, a comparative evaluation of monocyte infection with C. pneumoniae [28] showed a drastically reduced infectivity of C. pneumoniae in human monocytes at 24 and $48 \mathrm{~h}$ after infection, and no infective C. pneumoniae was detectable at later time points.

Complementary to immunofluorescence and RT-PCR, we confirmed the presence of C. pneumoniae in infected monocytes using an oligonucleotide DNA microarray for the detection of intracellular pathogens Bartonella, Bordetella, Chlamydia and Mycoplasma. DNA extracted from monocytes infected with C. pneumoniae yielded a positive signal at 6 and $48 \mathrm{~h}$ post infection for the high and low dose protocol, suggesting that the prototype DNA array has a potential to be developed into a useful diagnostic tool.

As a further method to trace monocyte infection with C. pneumoniae, we assessed the ability of Raman microspectroscopy to discriminate between infected monocytes and non-infected cells. Raman microspectroscopy, a combination of Raman spectroscopy and confocal microscopy, is an emerging technique to study living cells, providing fingerprints of their chemical composition. It has been applied in a recent study to characterize 

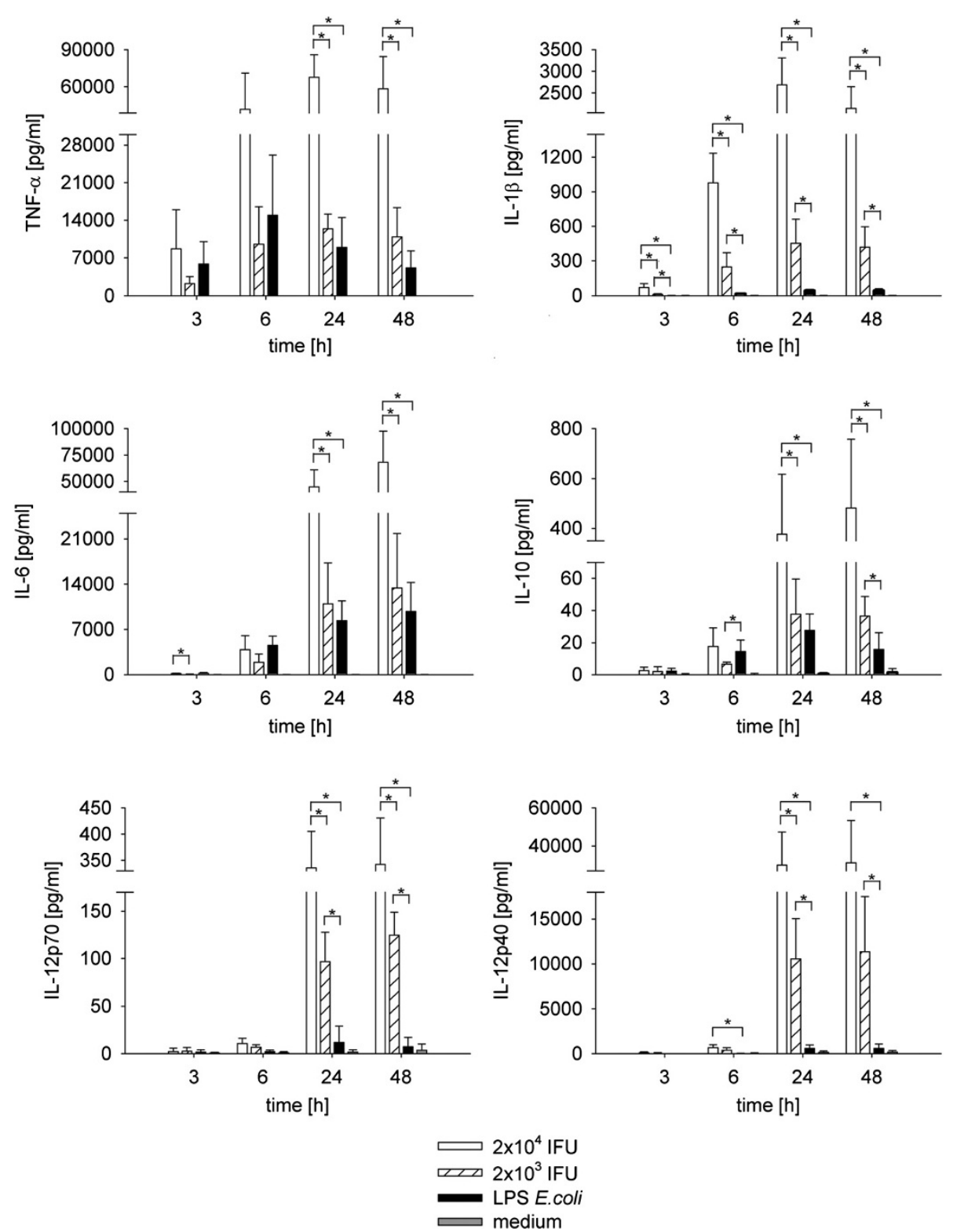

Figure 4 Cytokine induction in monocytes infected with C. pneumoniae or stimulated with LPS from E. coli. Human adherent monocytes $\left(2 \times 10^{5} /\right.$ well of 24 well plates) were infected with $2 \times 10^{4}$ (open bars) or $2 \times 10^{3}$ (hatched bars) inclusion forming units of $C$. pneumoniae or stimulated with $1 \mathrm{ng} / \mathrm{ml}$ LPS (black bars) for 3, 6, 24, and $48 \mathrm{~h}$. Medium alone served as negative control (grey bars). Mock controls did not differ from the values obtained for "medium alone". Concentrations are expressed as mean \pm SD for 3 independent experiments. *P $\leq 0.05$.

intracellular distribution of metabolites in Chlamydiainfected epithelial cells [29]. According to our results, this non-invasive technique allows for the discrimination of C. pneumoniae infected and non-infected monocytes, supporting its value to screen for intracellular pathogens. Of note, the changes in the wave number regions $1645-1660 \mathrm{~cm}^{-1}$ (unsaturated lipids) and $1327-1356 \mathrm{~cm}^{-1}$ (adenine) in infected monocytes in our study were comparable to data obtained in chlamydial infected epithelial cells [29].
Cytokine and chemokine release from infected monocytes were assessed in comparison to mediator release triggered by LPS. While several studies have been published on cytokine release by monocytic cell lines infected with C. pneumoniae [30,31], we used human blood monocytes purified from human peripheral blood mononuclear cells (PBMCs) by negative depletion and adherence to tissue culture plates. While release of TNF- $\alpha$ and IL-6 did not differ significantly for stimulation with low dose C. pneumoniae and LPS, C. pneumoniae induced 

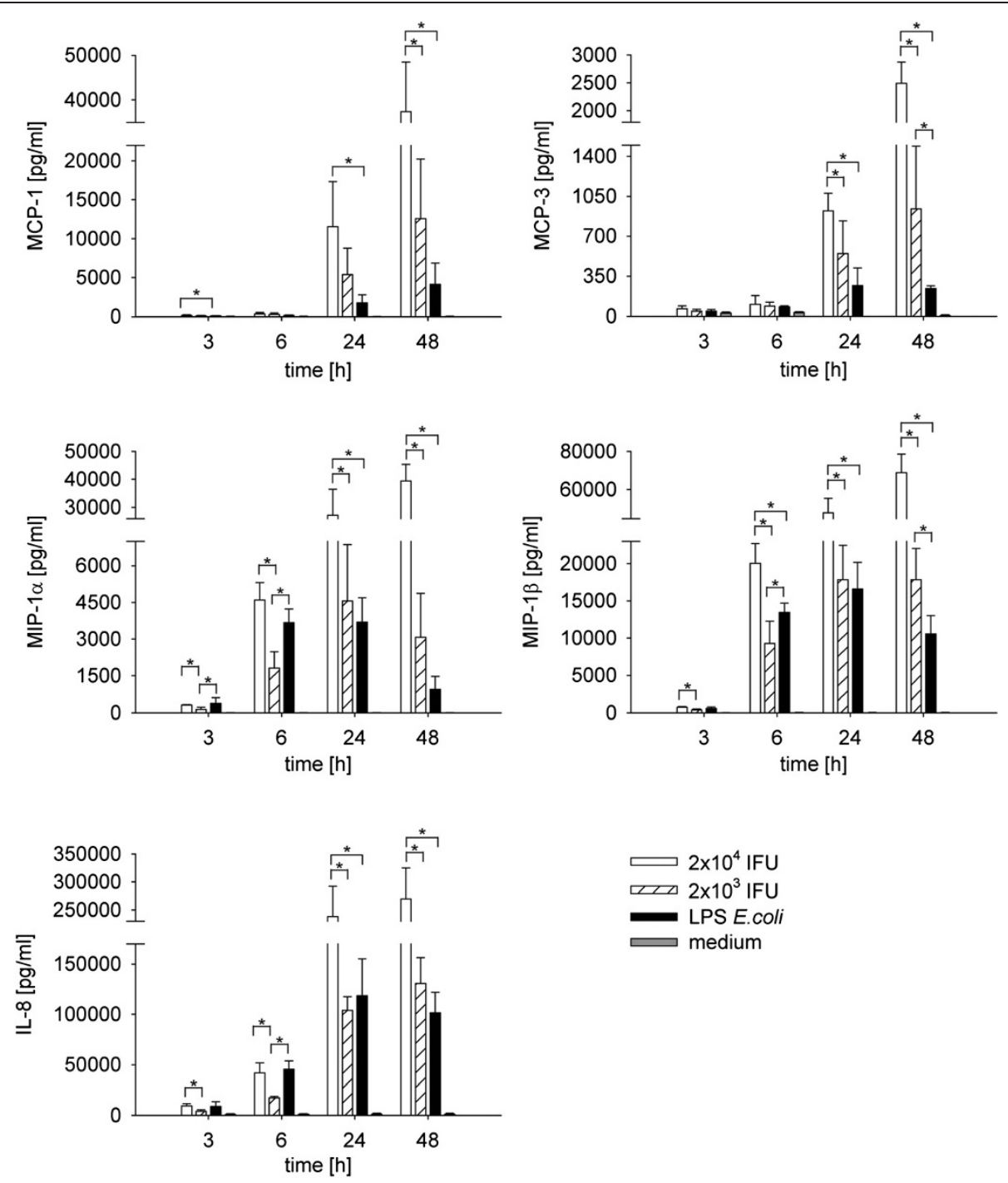

Figure 5 Chemokine induction in monocytes infected with C. pneumoniae or stimulated with LPS from E. coli. Human adherent monocytes $\left(2 \times 10^{5} /\right.$ well of 24 well plates) were infected with $2 \times 10^{4}$ (open bars) or $2 \times 10^{3}$ (hatched bars) inclusion forming units of $C$. pneumoniae or stimulated with $1 \mathrm{ng} / \mathrm{ml}$ LPS (black bars) for 3, 6, 24 and $48 \mathrm{~h}$. Medium alone served as negative control (grey bars). Mock controls did not differ from the values obtained for "medium alone". Concentrations are expressed as mean \pm SD for 3 independent experiments. * $\mathrm{P} \leq 0.05$.

significantly higher levels of IL-1 $\beta$, IL-12p40, and IL-12p70 than lipopolysaccharide. Secretion of IL-1 $\beta$ is tightly controlled and requires a first danger signal to produce pro-IL-1 $\beta$ and a second intracellular signal to induce caspase-1 dependent secretion of mature IL-1 $\beta[32,33]$. Due to constitutive activation of caspase- 1 , monocytes are able to secrete IL-1 $\beta$ upon stimulation with single ligands, while this ability is lost after monocyte adhesion [34]. Consistently, adherent monocytes in our study failed to release significant amounts of IL- $1 \beta$ upon stimulation with LPS alone, whereas infection with C. pneumoniae, which provides both an extracellular and an intracellular stimulus, resulted in strong induction of IL-1 $\beta$. The same pattern was observed for IL-12, confirming that TLR ligands alone are not sufficient to induce production of the IL-12 heterodimer [35].

Infection with C. pneumoniae induced substantial chemokine release from adherent monocytes in our model. MCP-1, MIP- $1 \alpha$, and IL- 8 secretion were comparable for low-dose chlamydial infection and stimulation with LPS, correlating with similar TNF- $\alpha$ secretion for the two stimuli, adding evidence to the finding that MCP-1, MIP- $1 \alpha$ and IL-8 induction depend on TNF- $\alpha$ [36].

\section{Conclusion}

The intracellular pathogen C. pneumoniae could be detected in human blood monocytes using a combination of immunofluorescence and RT-PCR, but we found no evidence 
for chlamydial replication. In addition, the oligonucleotide DNA microarray for the detection of intracellular pathogens as well as Raman microspectroscopy provided robust values to track infection of immune cells with intracellular pathogens. Infection of human blood monocytes with C. pneumoniae resulted in cytokine and chemokine profiles which differed significantly from stimulation with LPS, underscoring the ability of intracellular pathogens to alter innate immune response and to enhance mediator release via simultaneous activation of both membranebound and cytosolic pattern recognition receptors.

\section{Materials and methods}

\section{Cell culture media and reagents}

Phosphate-buffered saline (PBS), Eagle's minimum essential media (MEM) GlutaMAX, gentamicin/amphotericin B solution were obtained from Invitrogen (Lofer, Austria). RPMI-1640, MEM non-essential amino acid, human male AB serum (sterile-filtered), cycloheximide, 4-(2-hydroxyethyl)-1piperazineethanesulfonic acid (HEPES), fetal bovine serum (FBS), and lipopolysaccharide (LPS) from E. coli (055:B5, purified by gel filtration) were purchased from SigmaAldrich (St Louis, MO, USA). Fluorescein isothiocyanate (FITC)-conjugated anti-CD45 monoclonal antibody (mAb), R-phycoerythrin (PE)-conjugated CD14 mAb and the respective IgG control antibodies were from Becton Dickinson (Vienna, Austria).

\section{Propagation of $C$. pneumoniae}

C. pneumoniae strain CWL-029 was obtained from the American Type Culture Collection (ATCC, VR-1310) and propagated in HEp-2 cells (ATCC, CCL23) as previously reported $[22,37,38]$. In brief, HEp-2 cells were passaged in Eagle's MEM GlutaMAX supplemented with $10 \mu \mathrm{g} / \mathrm{ml}$ gentamicin, $0.25 \mu \mathrm{g} / \mathrm{ml}$ amphotericin $\mathrm{B}$, 1 vol\% MEM non-essential amino acids and $10 \mathrm{vol} \%$ heatinactivated FBS. Confluent monolayers were infected with C. pneumoniae and grown in the medium described above containing $1 \mu \mathrm{g} / \mathrm{mL}$ cycloheximide, but lacking antibiotics. Cells were spun at $1700 \mathrm{~g}$ for $1 \mathrm{~h}$ at $35^{\circ} \mathrm{C}$ to enhance infectivity. At $72 \mathrm{~h}$ post infection (hpi) at $35^{\circ} \mathrm{C}$ and $5 \% \mathrm{CO}_{2}$, the cell monolayer was disrupted using a cell scraper and zirconium dioxide beads. Chlamydial EBs were obtained by sequential centrifugation of the lysates at $600 \mathrm{~g}$ $(10 \mathrm{~min})$ and at $30,000 \mathrm{~g}\left(1 \mathrm{~h} ; 4^{\circ} \mathrm{C}\right)$. The pelleted EBs were suspended in sucrose-phosphate-glutamic acid buffer

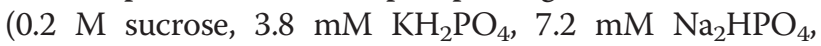
$5 \mathrm{mM}$ L-glutamic acid, $\mathrm{pH} 7.4$ ) and stored at $-80^{\circ} \mathrm{C}$. The number of chlamydial inclusion forming units (IFU) per $\mathrm{mL}$ was determined by infectivity titration of EBs in HEp-2 cells for $48 \mathrm{~h}$ at $35^{\circ} \mathrm{C}$, followed by immunofluorescence staining as described below. To exclude mycoplasma contamination, cell culture and chlamydial stocks were regularly tested using the Venor ${ }^{\mathrm{rm}} \mathrm{GeM}$ Mycoplasma Detection Kit (Minerva Biolabs, Berlin, Germany).

\section{Isolation and culture of monocytes}

PBMCs were isolated from leukocyte reduction system (LRS) chambers of a TrimaAccel ${ }^{\odot}$ blood collector after approval by the ethics committee of the Medical University Vienna and written informed consent were obtained from all participants (ECS2177/2013). Blood from LRS chambers was diluted 1:8 ( $\mathrm{vol} / \mathrm{vol})$ with PBS containing $2 \mathrm{mM}$ ethylene diamine tetraacetic acid (PBS/EDTA), and PBMCs were enriched by Ficoll gradient centrifugation. Monocytes were isolated by negative depletion with the monocyte isolation kit II (Miltenyi Biotec, Bergisch Gladbach, Germany) yielding $>80 \%$ CD14 positive cells as confirmed by flow cytometry. Viability was $>95 \%$ as determined by exclusion of 7-ADD.

Monocytes were resuspended at a concentration of $4 \times 10^{5} / \mathrm{mL}$ in serum-free RPMI-1640 supplemented with $20 \mathrm{mM}$ HEPES and cultured as described [39]. Aliquots of $0.5 \mathrm{~mL} /$ well of the monocyte suspension were seeded onto 24 well flat-bottomed tissue culture plates (Corning Incorporated, NY, USA). After $3 \mathrm{~h}$ at $37^{\circ} \mathrm{C}$, the monocyte monolayer was gently washed with serum-free RPMI-1640 to remove non-adherent cells. Adherent monocytes were kept in RPMI-1640 medium complete containing $20 \mathrm{mM}$ HEPES and 10 vol\% human $\mathrm{AB}$ serum for an additional $24 \mathrm{~h}$ at $37^{\circ} \mathrm{C}$.

\section{Infection of adherent monocytes}

Adherent monocytes were inoculated with $2 \times 10^{3}$ or $2 \times 10^{4}$ chlamydial IFU/well, respectively, or with $1 \mathrm{ng} /$ $\mathrm{mL}$ LPS (positive control) in a final volume of $0.5 \mathrm{~mL}$ medium complete. For infection, cells were centrifuged $30 \mathrm{~min}$ at $600 \mathrm{~g}$ and incubated at $37^{\circ} \mathrm{C}$ in $5 \% \mathrm{CO}_{2} \cdot \mathrm{Cu}-$ mulative culture supernatants were collected after 3,6 , 24 and 48 h, respectively, without replacing with fresh media, centrifuged at $600 \mathrm{~g}$ for $5 \mathrm{~min}$ at $4^{\circ} \mathrm{C}$, and stored at $-80^{\circ} \mathrm{C}$ until quantification of cytokines. Mock controls were prepared following the propagation, harvest and purification procedure for EBs $[40,41]$, but in the absence of chlamydial infection.

\section{Recovery assay}

The monocyte monolayer exposed to C. pneumoniae for 6 and 48 h was washed with PBS, and cells were scraped and vortexed with zirconium dioxide beads. EBs were obtained from the lysates as described above and passaged onto HEp-2 cells. At 48 hpi, HEp-2 cells were fixed and stained for immunofluorescence as described.

\section{DNA isolation and quantification}

Adherent monocytes infected with C. pneumoniae for 6 and $48 \mathrm{~h}$ or uninfected cells were washed with PBS and 
cells were counted on plates prior to DNA isolation. Total genomic DNA was isolated and purified using the QIAmp Mini DNA kit (Qiagen, Hilden, Germany). Purified DNA was quantified at $485 / 530 \mathrm{~nm}$ using the Quant-iTdsDNA HS assay and the Qubit ${ }^{\mathrm{Tm}}$ fluorometer (Invitrogen, Lofer, Austria).

\section{Real-time quantitative PCR}

C. pneumoniae genomes were quantified by real-time quantitative PCR, targeting a 222 bp sequence present on Chlamydia 16S rDNA. The oligonucleotide primers and TaqMan probes were synthesized by Microsynth AG (Balgach, Switzerland) and used as described in detail previously [42]. RT-PCR was performed in a final volume of $20 \mu \mathrm{L}$ including $1 \mathrm{x}$ Master Mix and Taq polymerase (Mastermix 16S, Molzym, Bremen, Germany), forward primer $(0.75 \mu \mathrm{M})$, reverse primer $(0.75 \mu \mathrm{M})$, FAM-TAMRA probe $(0.75 \mu \mathrm{M})$ and 2 ng of DNA. Amplification and detection was performed for $10 \mathrm{~min}$ at $95^{\circ} \mathrm{C}$, followed by 50 cycles of $10 \mathrm{~s}$ at $95^{\circ} \mathrm{C}$ and $65 \mathrm{~s}$ at $60^{\circ} \mathrm{C}$. Standards of known concentration $\left(10^{1}, 10^{2}, 10^{3}, 10^{4}, 10^{5}\right.$ and $10^{6}$ copies) were prepared for the $16 \mathrm{~S}$ rDNA target gene from PCR amplified C. pneumoniae DNA by conventional PCR, and purified with a QIAmp Mini DNA kit, according to the manufacturer's instructions. Samples were run in triplicate and all reactions were carried out using the iCycler IQ system (BioRad, Vienna, Austria).

\section{Detection of intracellular pathogens by DNA microarray}

In addition to RT-PCR, a prototype oligonucleotide microarray was developed. DNA amplification and labeling was carried out with one universal primer pair targeting a specific region of the $16 \mathrm{~S}$ rRNA gene. Hybridization was performed with novel probes for Bartonella, Bordetella, Chlamydia and Mycoplasma, which were designed and modified as described [23,43]. Four replicates of each probe at a concentration of $50 \mu \mathrm{M}$ were printed onto silylated glass slides with reactive aldehyde groups (CSS100 Silylated Slides; CEL Associates, Texas, USA) by the contact arrayer Omnigrid from GeneMachines (San Carlos, CA, USA) with MP 3 pins (TeleChem, Sunnyvale, CA, USA) leading to spot size of $100 \mu \mathrm{m}$. A hybridization control probe (5' -TTA AAA CGA CGG CCA GTG AGC) was spotted on the array applying the same conditions as used for the target capture probes. DNA amplification and primer extension were performed according to [23] with modifications as described in detail in Additional file 1. Slides were scanned using an Axon Genepix 4000A microarray scanner (Axon, Union City, California) and data were analyzed as described [23].

\section{Raman microspectroscopy}

Monocytes infected with C. pneumoniae $\left(2 \times 10^{4}\right.$ IFU) were cultured for 6 and $48 \mathrm{~h}$ on glass bottom $\mu$-slides
(170 $\mu \mathrm{m}$ thickness; ibidi GmbH, Munich, Germany). Samples were fixed with $4 \%$ paraformaldehyde for $4 \mathrm{~min}$ and washed 3 times with PBS. Raman spectroscopy was performed by CellTool (Bernried, Germany) using the Bio-Ram ${ }^{\oplus}$ system and the Bio-Ram ${ }^{\oplus}$ software. Raman spectra of 60 cells per assay were recorded with a $785 \mathrm{~nm}$ laser (80 $\mathrm{mW})$, applying an accumulated time of $3 \times 10 \mathrm{sec}$. Data of the biologically relevant region $\left(700-3000 \mathrm{~cm}^{-1}\right)$ were pre-treated with a median filter for noise reduction, unit vector normalisation and subsequent multivariate data analysis were done with the statistical software the Unscrambler X 10.3 (Camo Software, Oslo, Norway). We performed Principle Component Analysis (PCA) using the NIPALS algorithm and cross validation, which is a common procedure for spectral data analysis.

\section{Quantification of cytokines and chemokines}

The levels of tumor necrosis factor-alpha (TNF- $\alpha$ ), interleukin (IL)-1 $\beta$, IL-6, IL-12p70, IL-12p40, IL-10, monocyte chemotactic protein (MCP)-1 (CCL-2), MCP-3 (CCL-7), macrophage inflammatory protein (MIP)-1 $\alpha$ (CCL-3), MIP-1 $\beta$ (CCL-4), and IL-8 (CXCL-8) were determined in culture supernatants using the Bio-Plex 200 system (Bio-Rad, Vienna, Austria).

\section{Immunofluorescence}

Infected HEp-2 cells or monocytes were cultured on $\mu$-slides (ibidi GmbH, Munich, Germany) at 6 or $48 \mathrm{hpi}$, washed with PBS and fixed in $0.5 \mathrm{~mL}$ of methanol for $10 \mathrm{~min}$. To visualize chlamydial inclusions, cells were stained with FITC-conjugated anti-Chlamydia-LPS mAb and human cells were counterstained with Evans Blue (Pathfinder, Chlamydia Culture Confirmation System, Bio-Rad, Vienna, Austria). The cells were mounted in Fluoromount-GTM containing DAPI (Southern Biotech, Birmingham, UK) and fluorescence images were acquired with a Zeiss LSM 700 laser scanning confocal microscope (Carl Zeiss SAS, Jena, Germany) using a 40x oil objective/ 1.3 NA or $63 x$ oil objective/1.4 NA.

\section{Flow cytometry}

Purity and viability of monocytes were examined by determination of CD14 positive cells and 7-aminoactinomycin D (7-AAD) exclusion. Monocytes were stained with unconjugated 7-AAD (BioLegend, Fell, Germany), FITCconjugated anti-CD45 and PE-conjugated CD14 or with the respective IgG control antibody in PBS supplemented with 2 vol\% FBS, $0.1 \mathrm{w} \%$ sodium azide at $4^{\circ} \mathrm{C}$ for $30 \mathrm{~min}$. After one washing step, cells were analyzed on a Beckman Coulter FC 500 flow cytometer (Beckman Coulter, Vienna, Austria) and data were analyzed using the FlowJo software (Tree Star Inc, Ashland, OR). 


\section{Statistical analysis}

Statistical analysis was performed using the software package SPSS Statistics for Windows, version 18.0 (SPSS Inc., Chicago, Illinois, USA). When comparing two groups, data were analyzed by the nonparametric Wilcoxon rank sum test. Data are expressed as means \pm SD. Significance was accepted at $\mathrm{P} \leq 0.05$.

\section{Additional file}

Additional file 1: Materials and methods of the DNA microarray analysis.

\section{Competing interests}

The authors declare that they have no competing interests.

\section{Authors' contributions}

TB participated in design of the study, carried out monocyte isolation and infection, participated in validation of the microarray and drafted the manuscript; HWM participated in design of the study and of the microarray; KV participated in development of the microarray and data analysis; BMR participated in monocyte isolation and infection; GS provided DNA for development of the microarray and supported in array development; MBF provided leukocyte reduction chambers, participated in coordination of the study and in writing of the manuscript; WW participated in design and coordination of the study and in writing of the manuscript. All authors read and approved the final manuscript.

\section{Acknowledgements}

The excellent technical support by Silvia Schönthaler is gratefully acknowledged. We are grateful to Dr. Karin Schütze and Dr. Rainer Gangnus (CellTool) for support with Raman microspectroscopy measurements.

\section{Author details}

${ }^{1}$ Christian Doppler Laboratory for Innovative Therapy Approaches in Sepsis, Danube University Krems, Krems, Austria. ${ }^{2}$ Austrian Institute of Technology, Molecular Medicine, Vienna, Austria. ${ }^{3}$ Department of Blood Group Serology and Transfusion Medicine, Medical University of Vienna, Vienna, Austria. ${ }^{4}$ Institute for Hygiene and Applied Immunology, Medical University of Vienna, Vienna, Austria. ${ }^{5}$ Department for Health Sciences and Biomedicine, Danube University Krems, Krems, Austria.

Received: 7 August 2014 Accepted: 1 December 2014 Published online: 09 December 2014

\section{References}

1. Finlay BB, McFadden G: Anti-immunology: evasion of the host immune system by bacterial and viral pathogens. Cell 2006, 124(4):767-782

2. Khan N, Gowthaman U, Pahari S, Agrewala JN: Manipulation of costimulatory molecules by intracellular pathogens: veni, vidi, vici!! PLoS Pathog 2012, 8(6):e1002676.

3. Kern JM, Maass V, Maass M: Molecular pathogenesis of chronic Chlamydia pneumoniae infection: a brief overview. Clin Microbiol Infect 2009, 15(1):36-41.

4. Saikku P: Seroepidemiology in Chlamydia pneumoniae- atherosclerosis association. Eur Heart J 2002, 23(4):263-264.

5. Von HL: Role of persistent infection in the control and severity of asthma: focus on Chlamydia pneumoniae. Eur Respir J 2002, 19(3):546-556.

6. Contini C, Grilli A, Badia L, Guardigni V, Govoni M, Seraceni S: Detection of Chlamydophila pneumoniae in patients with arthritis: significance and diagnostic value. Rheumatol Int 2011, 31(10):1307-1313.

7. Tang YW, Sriram S, Li H, Yao SY, Meng S, Mitchell WM, Stratton CW: Qualitative and quantitative detection of Chlamydophila pneumoniae DNA in cerebrospinal fluid from multiple sclerosis patients and controls. Plos one 2009, 4(4):e5200.
8. Balin BJ, Little CS, Hammond CJ, Appelt DM, Whittum-Hudson JA, Gerard HC Hudson AP: Chlamydophila pneumoniae and the etiology of late-onset Alzheimer's disease. J Alzheimers Dis 2008, 13(4):371-380.

9. Di Pietro M, Schiavoni G, Sessa V, Pallotta F, Costanzo G, Sessa R: Chlamydia pneumoniae and osteoporosis-associated bone loss: a new risk factor? Osteoporos Int 2013, 24(5):1677-1682.

10. Rizzo A, Di Domenico M, Carratelli CR, Mazzola N, Paolillo R: Induction of proinflammatory cytokines in human osteoblastic cells by Chlamydia pneumoniae. Cytokine 2011, 56(2):450-457.

11. Wyrick PB: Chlamydia trachomatis persistence in vitro: an overview. J Infect Dis 2010, 201(Suppl 2):S88-95.

12. Schachter J: Biology of Chlamydia trachomatis. In Sexually Transmitted Diseases. Edited by Holmes KK SP, Mård PA, Lemon SM, Stamm WE, Piot P, Wasserheit JN. New York: McGraw-Hill; 1999:391-405.

13. Gaydos CA, Summersgill JT, Sahney NN, Ramirez JA, Quinn TC: Replication of Chlamydia pneumoniae in vitro in human macrophages, endothelial cells, and aortic artery smooth muscle cells. Infect Immun 1996, 64(5):1614-1620.

14. Byrne Gl, Kalayoglu MV: Chlamydia pneumoniae and atherosclerosis: links to the disease process. Am Heart J 1999, 138(5 Pt 2):S488-490.

15. Lin TM, Campbell LA, Rosenfeld ME, Kuo CC: Monocyte-endothelial cell coculture enhances infection of endothelial cells with Chlamydia pneumoniae. J Infect Dis 2000, 181(3):1096-1100.

16. Quinn TC, Gaydos CA: In vitro infection and pathogenesis of Chlamydia pneumoniae in endovascular cells. Am Heart J 1999, 138(5 Pt 2):S507-511.

17. Rupp J, Koch M, van Zandbergen G, Solbach W, Brandt E, Maass M: Transmission of Chlamydia pneumoniae infection from blood monocytes to vascular cells in a novel transendothelial migration model. FEMS Microbiol Lett 2005, 242(2):203-208.

18. Moazed TC, Kuo CC, Grayston JT, Campbell LA: Evidence of systemic dissemination of Chlamydia pneumoniae via macrophages in the mouse. J Infect Dis 1998, 177(5):1322-1325.

19. Contini C, Seraceni S, Cultrera R, Castellazzi M, Granieri E, Fainardi E: Chlamydophila pneumoniae Infection and Its Role in Neurological Disorders. Interdiscip Perspect Infect Dis 2010, 2010:273573.

20. Di Pietro M, Filardo S, Cazzavillan S, Segala C, Bevilacqua P, Bonoldi E, D'Amore ES, Rassu M, Sessa R: Could past Chlamydial vascular infection promote the dissemination of Chlamydia pneumoniae to the brain? J Biol Regul Homeost Agents 2013, 27(1):155-164.

21. Peters RP, van Agtmael MA, Danner SA, Savelkoul PH, Vandenbroucke-Grauls CM: New developments in the diagnosis of bloodstream infections. The Lancet infectious diseases 2004, 4(12):751-760.

22. Maass M, Harig U: Evaluation of culture conditions used for isolation of Chlamydia pneumoniae. Am J Clin Pathol 1995, 103(2):141-148.

23. Wiesinger-Mayr H, Vierlinger $K$, Pichler R, Kriegner A, Hirschl AM, Presterl E, Bodrossy L, Noehammer C: Identification of human pathogens isolated from blood using microarray hybridisation and signal pattern recognition. BMC microbiology 2007, 7:78.

24. Movasaghi Z, Rehman S, Rehman IS: Raman spectroscopy of biological tissues. App/ Spectrosc Rev 2007, 42(5):493-541.

25. Rupp J, Pfleiderer L, Jugert C, Moeller S, Klinger M, Dalhoff K, Solbach W, Stenger S, Laskay T, van Zandbergen G: Chlamydia pneumoniae hides inside apoptotic neutrophils to silently infect and propagate in macrophages. PloS one 2009, 4(6):e6020.

26. Wolf K, Fischer E, Hackstadt T: Degradation of Chlamydia pneumoniae by peripheral blood monocytic cells. Infect Immun 2005, 73(8):4560-4570.

27. Airenne S, Surcel HM, Alakarppa H, Laitinen K, Paavonen J, Saikku P, Laurila A: Chlamydia pneumoniae infection in human monocytes. Infect Immun 1999, 67(3):1445-1449.

28. Marangoni A, Bergamini C, Fato R, Cavallini C, Donati M, Nardini P, Foschi C, Cevenini R: Infection of human monocytes by Chlamydia pneumoniae and Chlamydia trachomatis: an in vitro comparative study. BMC research notes 2014, 7:230.

29. Szaszak M, Chang JC, Leng W, Rupp J, Ojcius DM, Kelley AM: Characterizing the intracellular distribution of metabolites in intact Chlamydia-infected cells by Raman and two-photon microscopy. Microbes and infection/ Institut Pasteur 2013, 15(6-7):461-469.

30. Heinemann M, Susa M, Simnacher U, Marre R, Essig A: Growth of Chlamydia pneumoniae induces cytokine production and expression of CD14 in a human monocytic cell line. Infect Immun 1996, 64(11):4872-4875.

31. Mamata Y, Hakki A, Newton C, Burdash N, Klein TW, Friedman H: Differential effects of Chlamydia pneumoniae infection on cytokine levels in human T 
lymphocyte- and monocyte-derived cell cultures. Int J Med Microbio/ 2007, 297(2):109-115.

32. Abdul-Sater AA, Said-Sadier N, Padilla EV, Ojcius DM: Chlamydial infection of monocytes stimulates IL-1 beta secretion through activation of the NLRP3 inflammasome. Microbes and infection/Institut Pasteur 2010, 12(8-9):652-661.

33. Eitel J, Meixenberger K, van Laak C, Orlovski C, Hocke A, Schmeck B, Hippenstiel S, N'Guessan PD, Suttorp N, Opitz B: Rac1 regulates the NLRP3 inflammasome which mediates IL-1 beta production in Chlamydophila pneumoniae infected human mononuclear cells. PloS one 2012, 7(1):e30379.

34. Netea MG, Nold-Petry CA, Nold MF, Joosten LA, Opitz B, van der Meer JH, van de Veerdonk FL, Ferwerda G, Heinhuis B, Devesa I, et al: Differential requirement for the activation of the inflammasome for processing and release of IL-1 beta in monocytes and macrophages. Blood 2009, 113(10):2324-2335

35. Trinchieri G: Interleukin-12 and the regulation of innate resistance and adaptive immunity. Nat Rev Immunol 2003, 3(2):133-146.

36. Netea MG, Selzman CH, Kullberg BJ, Galama JM, Weinberg A, Stalenhoef AF, Van der Meer JW, Dinarello CA: Acellular components of Chlamydia pneumoniae stimulate cytokine production in human blood mononuclear cells. Eur J Immunol 2000, 30(2):541-549.

37. Roblin PM, Dumornay W, Hammerschlag MR: Use of HEp-2 cells for improved isolation and passage of Chlamydia pneumoniae. J Clin Microbiol 1992, 30(8):1968-1971.

38. Campbell LA, Kuo CC: Cultivation and laboratory maintenance of Chlamydia pneumoniae. Curr Protoc Microbiol 2009, 11(11B):11.

39. Wolf HM, Fischer MB, Puhringer $H$, Samstag A, Vogel E, Eibl MM: Human serum IgA downregulates the release of inflammatory cytokines (tumor necrosis factor-alpha, interleukin-6) in human monocytes. Blood 1994, 83(5):1278-1288

40. Datta B, Njau F, Thalmann J, Haller H, Wagner AD: Differential infection outcome of Chlamydia trachomatis in human blood monocytes and monocyte-derived dendritic cells. BMC microbiology 2014, 14:209.

41. Sommer K, Njau F, Wittkop U, Thalmann J, Bartling G, Wagner A, Klos A: Identification of high- and low-virulent strains of Chlamydia pneumoniae by their characterization in a mouse pneumonia model. FEMS immunology and medical microbiology 2009, 55(2):206-214.

42. Goldschmidt P, Rostane H, Sow M, Goepogui A, Batellier L, Chaumeil C: Detection by broad-range real-time PCR assay of Chlamydia species infecting human and animals. Br J Ophthalmol 2006, 90(11):1425-1429.

43. Ludwig W, Strunk O, Westram R, Richter L, Meier H, Yadhukumar, Buchner A, Lai T, Steppi S, Jobb G: ARB: a software environment for sequence data. Nucleic acids research 2004, 32(4):1363-1371.

doi:10.1186/s12865-014-0060-1

Cite this article as: Buchacher et al:: Human blood monocytes support persistence, but not replication of the intracellular pathogen C. pneumoniae. BMC Immunology 2014 15:60.

\section{Submit your next manuscript to BioMed Central and take full advantage of:}

- Convenient online submission

- Thorough peer review

- No space constraints or color figure charges

- Immediate publication on acceptance

- Inclusion in PubMed, CAS, Scopus and Google Scholar

- Research which is freely available for redistribution

Submit your manuscript at www.biomedcentral.com/submit
Ciomed Central 